\title{
PENENTUAN POTENSI SUMBERDAYA HIPOTETIK TIMAH PRIMER DI DAERAH AIR INAS KEPULAUAN BANGKA BELITUNG
}

\author{
Andi Darmawansyah ${ }^{1}$, Makhrani $^{1 *}$, Syamsuddin $^{1}$ \\ ${ }^{1}$ Program Studi Geofisika, Fakultas Matematika dan Ilmu Pengetahuan Alam, \\ Universitas Hasanuddin
}

Penulis koresponden. Alamat email: makhranigeofisika@gmail.com

\begin{abstract}
Abstrak
Penelitian ini bertujuan untuk menentukan zona lemah yang diindikasikan sebagai vein dan menentukan besar sumberdaya hipotetiknya. Data penelitian merupakan data sekunder, terdiri dari 5 lintasan dengan spasi 10 meter dengan panjang lintasan bervariasi. Interpretasi dilakukan dengan menganalisis model penampang 2D dan 3D hasil pengukuran resisitivitas dan chargebilitas bawah permukaan. Hasil interpretasi menunjukkan bahwa persebaran zona lemah yang diindikasikan sebagai tempat terakumulasinya mineral yang mengandung timah cendrung mengarah ke Timur Laut, dimana nilai resistivitas yang rendah letaknya dekat permukaan dengan geometri berbentuk cekungan yang diinterpretasikan sebagai alluvial sedangkan nilai resistivitas rendah yang letaknya jauh dari permukaan diinterpretasikan sebagai zona struktur yang kaya akan rekahan. Dugaan potensi vein yang mengandung timah berada pada nilai resistivitas $500 \mathrm{Ohm}-5000 \mathrm{Ohm}$ dan nilai Chargebilitas 5 - 100 msec. Besar sumberdaya hipotetik daerah penelitian adalah 741,382 ton.
\end{abstract}

Kata kunci: Zona lemah, resistivitas, chargebilitas, Timah Primer

\begin{abstract}
This research focused on determining fracture zone which indicated as vein and it's estimated resources. The data used is secondary data, consist of 5 lines with the gap is 10 meters and diverge length of the lines. Interpretation was undertaken by analyzing 2D and 3D resistivity and chargebility section. The result enlightened that fracture zona distribution which assumed as the zone of the tin contained headed on north east, which the low resistivity value placed near the surface and shaped like syncline assumed as alluvial whereas the low resisitivity value that far from the surface interpreted as joint zone. Vein potency estiuation that composed of tin found in $500-5000$ and $5-$ $100 \mathrm{msec}$ with the prospects of estimated resources around the research aea is 741,3822 ton.
\end{abstract}

Keywords: Fracture zone, Resistivity, Chargebility, Primary tin

\section{Pendahuluan}

Endapan timah di dunia pada umumnya terdiri sekitar $20 \%$ endapan primer dan 80 $\%$ endapan sekunder atau endapan dari hasil pelapukan endapan primer, keterdapatan endapan timah pun tidak berada pada seluruh Negara. Keterdapatan endapan timah di Asia Tenggara membentang dari daratan Cina, Birma, Thailand, Malaysia hingga Indonesia (Ramadhan, 2015). 
Wilayah cadangan timah di Indonesia mencakup Pulau Karimun, Kundur, Singkep, dan sebagian di daratan Sumatera (Bangkinang) di utara terus ke arah selatan yaitu Pulau Bangka, Belitung, dan Karimata hingga ke daerah sebelah barat Kalimantan. Batuan pembawa timah yang ada di Indonesia adalah batuan granit yang berumur Trias (Kuncoro, 2009).

Penyebaran timah di Pulau Bangka merupakan kelanjutan dari Tin Mayor South East Asian Tin Belt yang membentang mulai dari Birma, Thailand dan Malaysia hingga berakhir di Indonesia. Di Kepulauan Bangka belitung sering dilakukan penelitian oleh para ahli geologi dan geofisika terkait dengan keberadaan timah. Salah satu metode yang sering digunakan yaitu metode geolistrik Induksi Polarisasi (IP). Metode ini digunakan untuk mencari informasi mengenai pola penyebaran mineralisasi (Kuncoro, 2009).

Salah satu penelitian dilakukan oleh Ramadhan, 2015 di daerah Air Inas tentang "Studi Mineralisasi Endapan Timah Primer Berdasarkan Kajian Geologi Permukaan dan Analisis XRF Unsur Sn" yang menyebutkan bahwa mineralisasi yang ditemukan dalam bentuk urat (vein) dengan presentasi kadar Sn yang berbeda-beda di beberapa titik. Melalui data dari hasil penelitian tersebut, perlu dilakukan survei geofisika lebih lanjut untuk mengetahui zona lemah yang diindikasikan sebagai vein, dan kemudian menghitung potensi sumber daya hipotetik daerah tersebut.

\section{Induced Polarization Method}

Metode Geolistrik IP "Induced Polarization Method" adalah salah satu metode geofisika yang menggunakan arus listrik. Jika arus listrik yang diinjeksikan kebawah permungkaan bumi dihentikan maka tampak bahwa beda potensial antara kedua elektroda tidak langsung menunjukan angka nol (0). Arus turun secara perlahan dalam selang waktu tertentu. Sebaliknya apabila arus dihidupkan maka beda potensial akan kembali pada posisi semula dalam waktu yang sama (Virman, 1999).

Gejala polarisasi terimbas dalam batuan termineralisasikan terutama ditentukan reaksi elektrokimia pada bidang batas antara mineral-mineral logam dan larutan dalam batuan. Geolistrik IP dapat dilakukan dengan mengalirkan arus terkontrol melalui bahan yang akan diselidiki (Virman, 1999).

\section{Metode Pengukuran IP Kawasan Waktu (Time Domain)}

Pengukuran IP kawasan waktu merupakan metode yang dapat dimanfaatkan untuk menginvestigasi struktur permukaan bumi yang mengandung deposit mineral. Dengan prinsip mengalirkan arus listrik kedalam bumi kemudian mengamati beda potensial yang terjadi setelah arus listrik dihentikan. Ketika arus diputus, idealnya beda potensial tersebut langsung menjadi nol/hilang, tetapi pada medium-medium tertentu akan menyimpan energi listrik (sebagai kapasitor) dan akan dilepaskan kembali. Jadi, walaupun arus sudah diputus, tetapi beda tegangan masih ada akan meluruh terhadap waktu dan berangsur-angsur hilang/nol. Efek ini dinamakan Efek Induksi Polarisasi. Parameter yang diperoleh dalam pengukuran ini adalah tegangan primer $\left(\mathrm{V}_{\mathrm{p}}\right)$ yang diperoleh ketika arus belum dimatikan dan tegangan sekunder $\left(\mathrm{V}_{\mathrm{s}}\right)$ adalah beda potensial yang terukur selama waktu peluruhan nilai tegangan hingga mencapai nilai nol. Untuk mengetahui seberapa besar nilai perbandingan efek polarisasi pada batuan yaitu dengan membandingkan nilai $\mathrm{V}_{\mathrm{p}}$ dan $\mathrm{V}_{\mathrm{s}}$ untuk selang waktu $\mathrm{t}_{1}$ kemudian dikalikan $100 \%$.

IP Effect $=\frac{V_{s}\left(t_{1}\right)}{V_{p}} \times 100 \%$ 


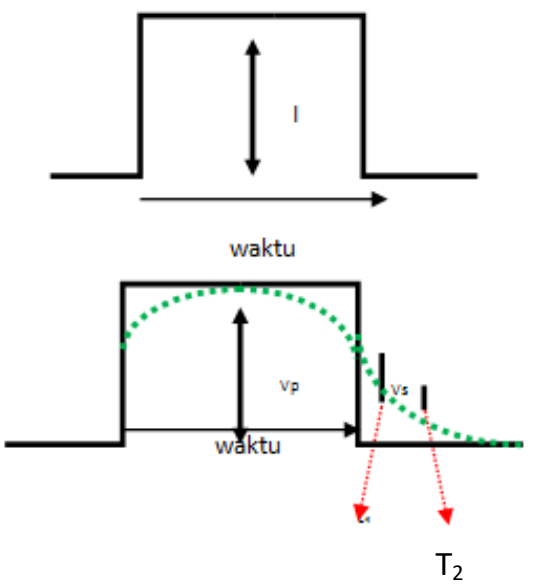

Gambar 1 Grafik arus listrik dan potensial dalam kawasan waktu

$\begin{array}{lcrr}\begin{array}{l}\text { Berdasarkan } \\ \text { chargebilitas }\end{array} & \text { Gambar } & \mathbf{1}, & \text { nilai } \\ \text { dengan }\end{array}$ membandingkan nilai $\mathrm{V}_{\mathrm{p}}$ dan nilai ratarata $\mathrm{V}_{\mathrm{s}}$ yang diperoleh dengan mengintegralkan nilai $\mathrm{V}_{\mathrm{s}}$ terhadap sampel waktu peluruhan yang kita pergunakan. Sampel waktu peluruhan yang digunakan merupakan batas integral dari persamaan tersebut dimana $t_{1}$ dan $t_{2}$ adalah batasbatas integrasi. (Virman, 1999)

$$
C=\frac{1}{V_{p}} \int_{t_{1}}^{t_{2}} V_{s}(t) d t
$$

Satuan dari chargebilitas adalah mili second.

\section{Prinsip Pengukuran}

Metode IP menggunakan konfigurasi dipol-dipol, yaitu kedua elektroda arus bergerak menjauhi kedua elektroda tegangan seperti pada gambar di bawah ini.

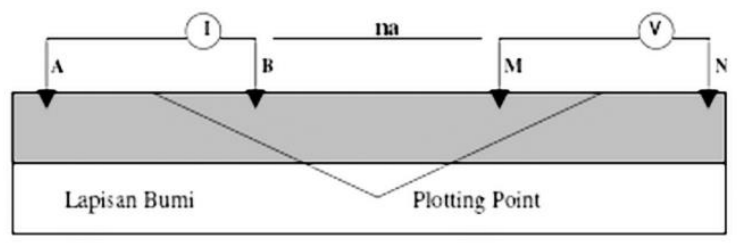

Gambar 2 Susunan elektroda konfigurasi dipol-dipol (Telford, 1990)

dengan $\mathrm{A}$ dan $\mathrm{B}=$ elektroda arus $\mathrm{r}_{1}=\mathrm{AM}$ $=(\mathrm{n}+1) \mathrm{a}$, dan $\mathrm{M}$ dan $\mathrm{N}=$ elektroda potensial, dengan ketentuan:
$\mathrm{r}_{2}=\mathrm{BM}=\mathrm{na}$

$\mathrm{AB}=\mathrm{MN}=\mathrm{a}$ (dalam satuan meter)

$\mathrm{r}_{3}=\mathrm{AN}=(\mathrm{n}+2) \mathrm{a}$

$\mathrm{r}_{4}=\mathrm{BN}=(\mathrm{n}+1) \mathrm{a}$

Faktor geometrinya :

$$
K=\pi n a(n+1)(n+2)
$$

Dengan $\mathrm{K}$ merupakan faktor geometri yang nilainya bervariasi bergantung pada jarak dari "a". kemudian dengan mensubtitusi nilai $\mathrm{K}$ dengan persamaan di atas dapat dihitung nilai resisitivitas tiap kedalaman adalah:

$$
\rho_{a}=\pi a n(n+1)(n+2) \frac{\Delta V}{I}
$$

(Telford, 1990)

\section{Metode Penelitian}

Lokasi penelitian terletak pada wilayah daerah kuasa pertambangan PT. Timah (Persero) Tbk, yang secara administratif terletak di daerah Air Inas, Kecamatan Toboali, Kabupaten Bangka Selatan Provinsi Kepulauan Bangka Belitung.

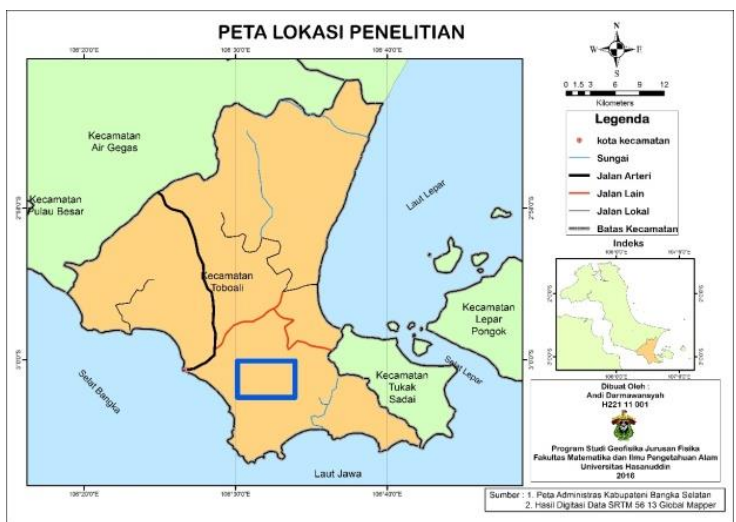

Gambar 4 Lokasi Penelitian

Prosedur penelitian meliputi tahap akuisisi data, pengolahan data dan interpretasi termasuk didalamnya penentuan zona lemah dan perhitungan sumber daya hipotetik (SDH) dengan menggunakan rumus berikut :

$S D H=\frac{A\left(m^{2}\right) \times d(m) \times \rho\left(k g / \mathrm{m}^{3}\right)}{1000}$ 

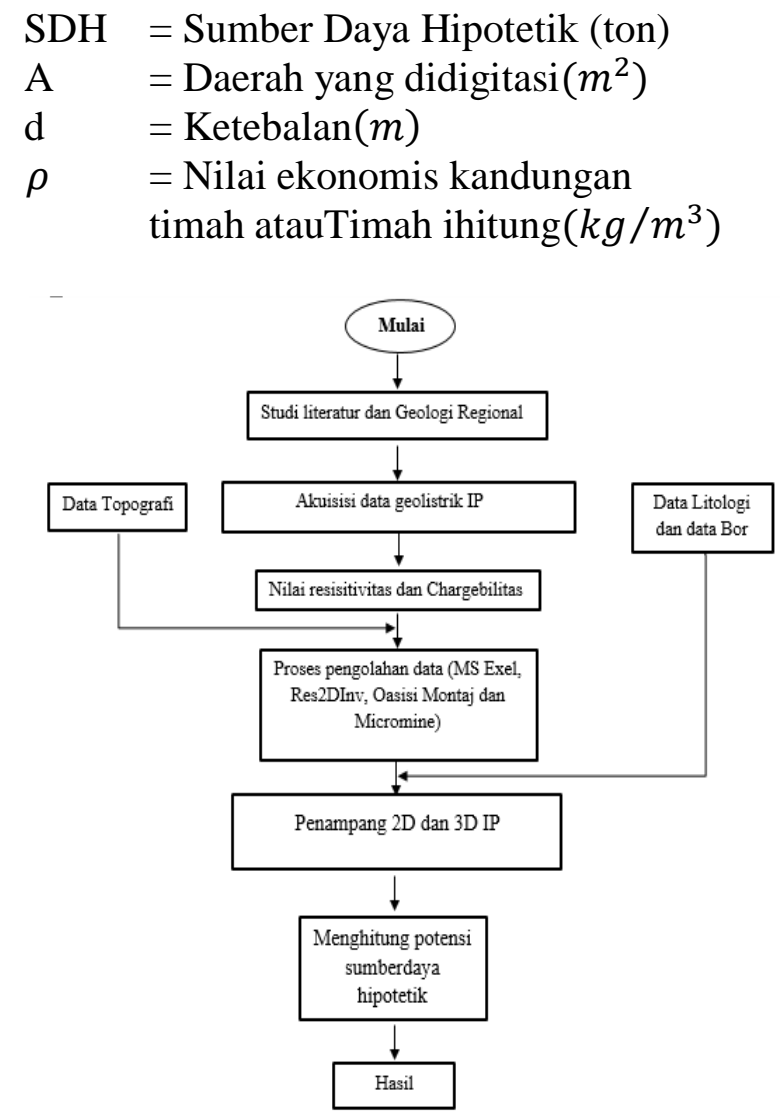

Gambar 5 Bagan Alir Penelitian

\section{Hasil dan Pembahasan}

Data yang digunakan pada penelitian ini merupakan data sekunder daerah air inas Kepulauan Bangka Belitung. Data yang digunakan sebanyak 5 lintasan dengan panjang lintasan yang berbeda yaitu mulai dari titik LA dengan panjang lintasan 400 meter, LB 1000 meter, LC 980 meter, LD 1000 meter, dan LE 780 meter. Spasi tiap elektroda yang digunakan adalah 10 meter, jarak antar lintasan LA-LB 50 meter, LBLC 35 meter LC-LD 50 meter, sedangkan letak lintasan LE berada sejajar dengan LA. Data yang diperoleh berupa nilai beda potensial (V), kuat arus (I), chargebilitas (m), dan Resistivitas (Rho) serta didukung data geologi permukaan serta data pengeboran.

Berikut adalah gambar peta lintasan pengukuran IP.

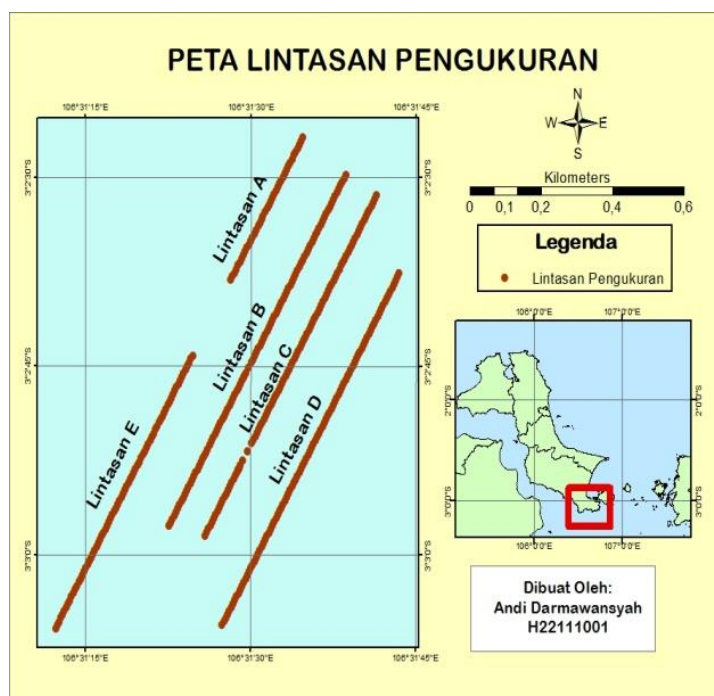

Gambar 6 Peta lintasan pengukuran

Penampang 2D

Penampang Resistivitas dan Chargebilitas dalam bentuk 2D dibuat pada masingmasing lintasan pengukuran dengan menggunakan software Res2Dinv. Berikut adalah gambaran penampang 2D untuk salah satu lintasan.

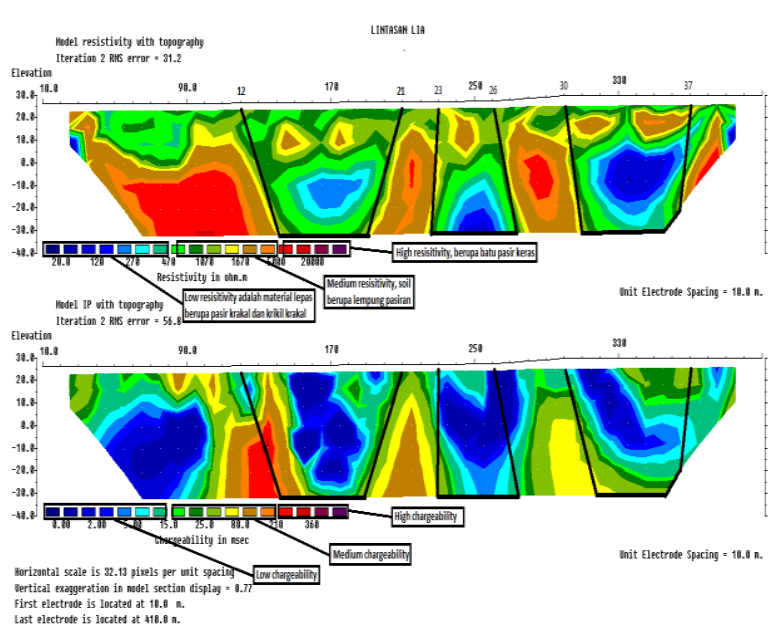

Gambar 7 Penampang Resistivitas dan Chargebilitas Lintasan INAS GLI-A

\section{Penampang $3 D$}

Penampang 2D yang telah dibuat di Res2DInv kemudian dibuat dalam model 3D di software Oasis montaj dengan memasukkan koordinat $\mathrm{X}, \mathrm{Y}, \mathrm{Z}$ dari setiap lintasan. 


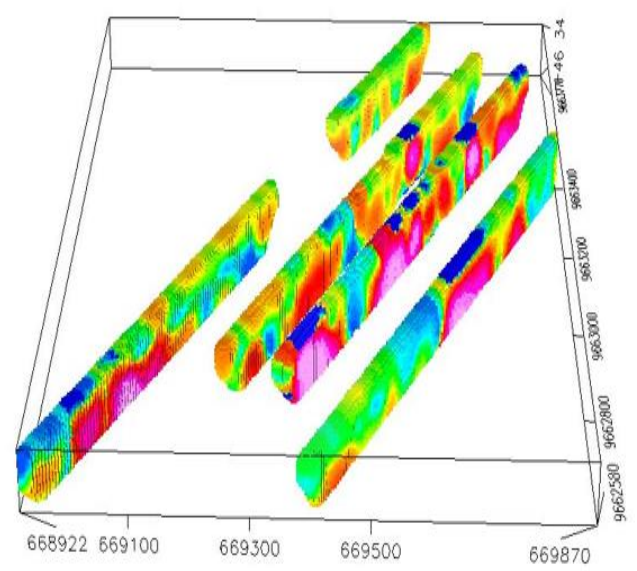

Gambar 8 Penampang 3D Resisitivitas

Pada penampang resistivitas di daerah Air Inas, memperlihatkan adanya nilai resistivitas cenderung variatif dimana nilai resisitiviy berada pada resistivitas rendah hingga resistivitas tinggi, dengan kisaran 20 - $50000 \Omega \mathrm{m}$ dan ditandai dengan warna biru, merah hingga merah muda. Pada lintasan LB dan LC memiliki zona yang nilai resistivitasnya dominan tinggi, dimana zona tersebut merupakan mineral sulfida yang berasosiasi dengan batuan sedimen dengan litologi lempung pasiran, sedangkan pada lintasan LA, LD dan LE di dominasi oleh resistivitas rendah hingga resistivitas sedang dengan nilai 20 hingga 5000 Ohm.m yang diperlihatkan dengan warna biru hingga merah bata yang terdiri dari material lepas berupa alluvial dengan litologi berupa pasir kerakal, kerikil kerakal dan lempung pasiran.

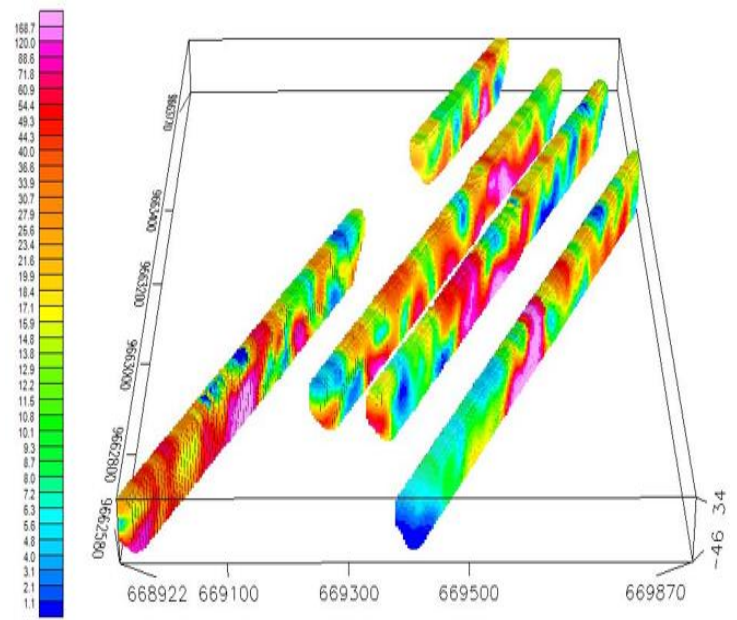

Gambar 9 Penampang 3D Chargebilitas
Pada penampang chargebilitas di daerah Air Inas, memperlihatkan adanya nilai chargebilitas cenderung tinggi, berkisar antara $26 \mathrm{msec}$ ke atas dan ditandai dengan warna ungu hingga merah muda. Zona tersebut diduga mineral sulfida yang berasosiasi dengan batuan sedimen, sedangkan nilai chargebilitas yang rendah, $25 \mathrm{msec}$ ke bawah yang diperlihatkan dengan warna merah hingga biru. Adanya variasi nilai pada semua lintasan pengukuran di indikasikan sebagai mineral pembawa timah primer diantaranya : turmalin, kuarsa, galena, monasit, arsenopirit, pirit dan kasiterit.

\section{Perhitungan Sumberdaya Hipotetik}

Setelah penampang 3D dibuat di software Oasis Montaj kemudian penampang dislice secara vertikal di kedalaman 15 meter dari permukaan untuk mendapatkan daerah yang dianggap sebagai intreast area. Slice pada kedalaman 15 meter dilakukan karena didaerah tersebut merupakan daerah bekas tambang PT. Timah sebelumnya hingga pada kedalaman tersebut dianggap masih di pengaruhi oleh noise permukaan, hal tersebut ditunjukkan oleh data geologi lapangan dan tingginya RMS Error pada data penampang Res2Dinv. Setelah dislice, kemudian dibuat tanda berupa ( daerah yang diarsir ) di software micromine untuk menghitung luasan yang dianggap sebagai zona lemah tempat terakumulasinya mineral-mineral yang mengandung timah, berikut gambar peta persebaran vein.

Software Micromine mengitung luasan yang telah didigitasi, yang kemudian dikalikan dengan ketebalan lapisan yang diinterpretasi banyak mengandung timah yang telah diketahui dari penampang $2 \mathrm{D}$ di Res2DInv. Luasan total yang telah didigitasi adalah 82735,79531 $\left(\mathrm{m}^{2}\right)$, TDH yang disimbolkan $\rho$ adalah $0,2\left(\mathrm{~kg} / \mathrm{m}^{3}\right)$ yaitu nilai dan satuan kekayaan timah di PT. Timah. Sumber daya hipotetik Timah Primer PT. Timah dalam satuan Ton. 
Perhitungan Sumber daya Hipotetik Timah primer :
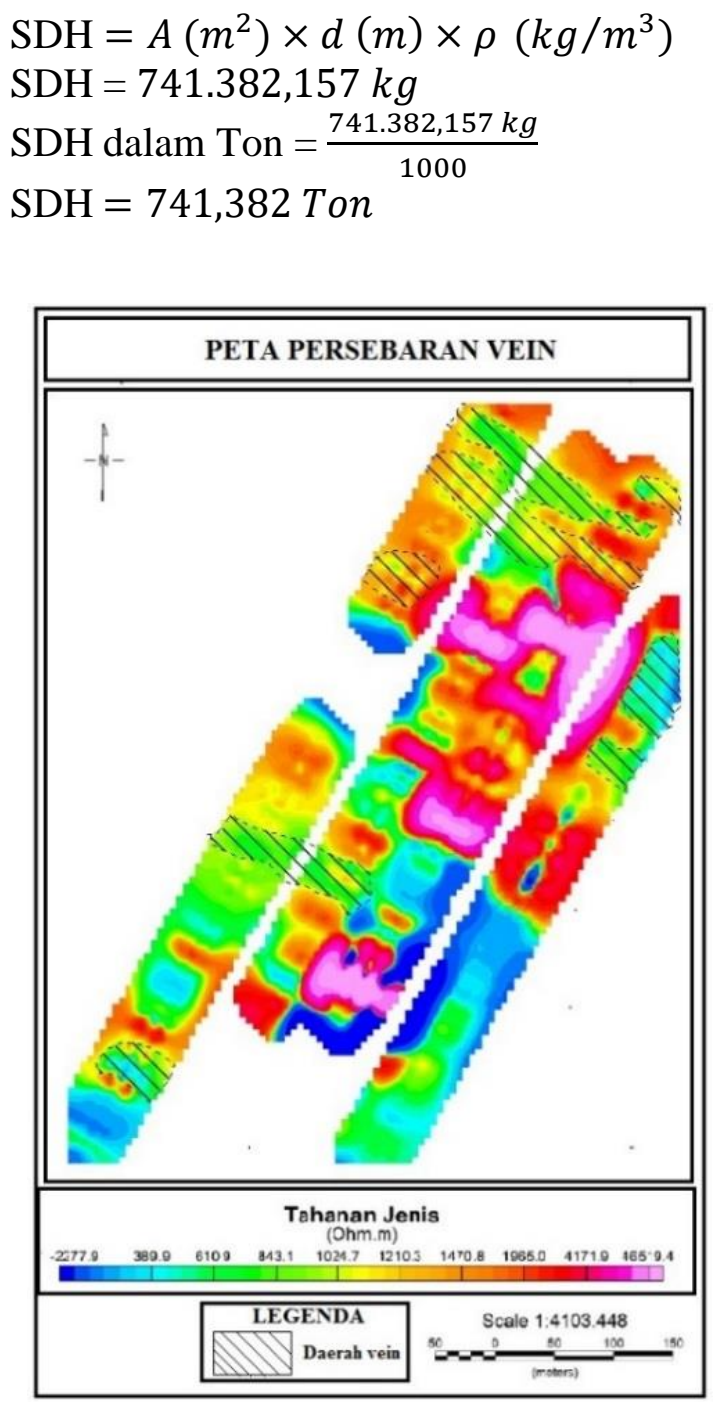

Gambar 10 Peta Persebaran Vein

Jadi, besar sumberdaya hipotetik timah primer di daerah penelitian ini sebesar 741,382 Ton

\section{Kesimpulan}

Dari hasil pengolahan data pengukuran IP berupa penampang IP 2D, 3D dan data bor menghasilkan zona lemah yang diindikasikan sebagai vein, tempat terakumulasinya mineral yang mengandung timah cenderung mengarah ke Timur Laut. Luas daerah prospek mengandung timah adalah sekitar $82.375,795 \mathrm{~m}^{2}$ dari luas daerah penelitian
1.322.479,864 $\mathrm{m}^{2}$ dengan sumber daya hipotetik sebesar 741,382 Ton.

\section{Daftar Pustaka}

Kuncoro, 2009, Geologi dan Alterasi Mineralisasi Daerah Sambuggiri dan Sekitarnya kecamatan Merawang, Kabupaten Bangka Induk, Kepulauan Bangka Belitung, Universitas Jendral Sudirman , Purwokerto.

Ramadhan, S., 2015, Studi Mineralisasi Endapan Timah Primer Berdasarkan Kajian Geologi Permukaan dan Analisis XRF Unsur Sn pada Wilayah Kerja Blok Primer PT. TIMAH (Persero) Tbk, Daerah Air Inas dan Sekitarnya, Bangka Selatan. Semarang , Universitas Dipanegara.

Telford, W.M. Geldart, L.P. Sheriff, R.E. dan Keys, D.A., 1976. Applied Geophysics, Cambridge University Press, Cambridge.

Virman,1999,Aplikasi Metode Polarisasi Terimbas untuk Eksplorasi Timah di Daerah Air Itam Kab, Belitung, Bangka Belitung, Tesis Magister ITB, Bandung. 